\title{
Note
}

\section{Economic Development and Infrastructure: The Case of Balochistan Province}

\author{
W. R. BROCK, J. J. VAN DIJK, E. B. K. VAN KOESVELD, and S. WAGENAAR
}

\begin{abstract}
In designing a future road network, public budget constraints force administrations to make choices. The objective of economic development requires that both efficiency and equity are taken into account. The present analysis operationalises these two concepts by social and economic accessibility in Balochistan. It suggests priorities which can serve as an input for the design of the future road network.
\end{abstract}

\section{INTRODUCTION}

It is beyond dispute that every country or region needs a certain level of basic infrastructure in order to attain economic development. With regard to developing countries, one might be tempted to consider any improvement a good step forward. Public budget constraints, however, force administrations to make choices. Consequently, the objectives for infrastructure need to be formulated clearly in order to evaluate new projects.

This paper attempts to contribute to a systematic approach to one of the components of infrastructure, that is, the road sector. Although it concentrates on Balochistan, a very poor and sparsely populated province of Pakistan, application to other regions or countries is feasible. The present analysis may also be extended to include more factors relevant for the road network. Whether this is possible is largely dependent on the availability of data.

Roads are not a goal as such. They are a key factor in striving for economic development. The relation between roads and economic development will be worked out in the following section. This relation then provides a sound theoretical basis for empirical analysis. Finally, both elements are used to discuss some policy implications for the road network in Balochistan.

\section{ECONOMIC DEVELOPMENT AND INFRASTRUCTURE}

Economic development can be defined as the simultaneous occurrence of a growing per capita income and improvement in the standard of living of low income

W. R. Brock, J. J. van Dijk, E. B. K. van Koesveld, and S. Wagenaar are associated with the Department of Economics, Erasmus University, Rotterdam, Holland. 
groups. In this widely accepted definition, the first element refers to efficiency, whereas the second element reflects equity. Stated differently, economic development is hard to obtain by taking only efficiency into account.

The general infrastructure can be viewed as a target as well as an instrument, depending on the point of view. The construction of a new road can be the physical target. For economic development, however, the infrastructure is much more of an instrument. The construction of a new road then aims at raising income levels or making basic services accessible to the population. By only stating that the infrastructure should be efficient, i.e., to attain maximum growth, the equity aspect is ignored. Economic development requires that both elements are taken into account and an optimum between the two should be searched for.

Viewing roads as an instrument for economic development introduces a spatial dimension into the analysis, as roads serve to facilitate transportation between spatially dispersed activities. Focusing on the efficiency of roads will often give rise to a spatial concentration of economic growth. Unfortunately, there is no automatic spread of these benefits all over the region from a growth centre. To stimulate trickledown effects necessitates the inclusion of an equity element into the network of roads. This clearly demonstrates the presence of a trade-off between efficiency and equity in the planning of roads for economic development.

Empirical analysis of the road network of Balochistan shows the following three main directions. After a brief analysis of the coverage and balance of the network in Balochistan, spatial linkages are discussed. Next, the important aspects of economic development, efficiency and equity, are studied for the road network. Equity is operationalised by the concept of social accessibility, and efficiency by economic accessibility.

To this aim, Table 1 shows the road densities (coverage) and the percentage of blacktop roads (balance) for the districts of Balochistan. As a result of the lack of suitable data, all Balochistan is divided into 17 instead of the actual 25 districts (1993). Additional information is provided in the note below the Table.

The districts of Chagai, Kohlu, Dera Bugti, Khuzdar, Kharan, and Turbat possess very low densities and quite unbalanced networks. Within Balochistan, the densities of Pangjur and Gawader are not unreasonable but their networks are extremely unbalanced. A remarkable situation holds for Nasirabad as the percentage of blacktop is very high, coupled with a relatively low density.

According to international standards, the present results confirm the unfavourable situation for Balochistan. Several districts within Balochistan are in the worst possible situation, as far as roads are concerned. Giving priority to the construction of roads in Balochistan seems obvious. Within the Province, however, several other priorities can be detected as well. 
Table 1

Coverage and Balance of Roads in Balochistan

\begin{tabular}{|c|c|c|}
\hline District & Road Density & \%Blacktop \\
\hline Quetta & 1.427 & 0.290 \\
\hline Pishin & 0.147 & 0.239 \\
\hline Chagai & 0.026 & 0.311 \\
\hline Loralai $^{1}$ & 0.057 & 0.302 \\
\hline Zhob $^{2}$ & 0.056 & 0.154 \\
\hline Sibi+Ziarat & 0.088 & 0.164 \\
\hline Kohlu & 0.042 & 0.010 \\
\hline Dera Bugti & 0.045 & 0.206 \\
\hline Nasirabad $^{3}$ & 0.082 & 0.553 \\
\hline Kachhi $^{4}$ & 0.070 & 0.323 \\
\hline Kalat & 0.056 & 0.356 \\
\hline Khuzdar $^{5}$ & 0.018 & 0.163 \\
\hline Kharan & 0.022 & 0.072 \\
\hline Lasbella & 0.065 & 0.374 \\
\hline Turbat & 0.043 & 0.022 \\
\hline Pangjur & 0.062 & 0.018 \\
\hline Gawader & 0.063 & 0.055 \\
\hline Average & 0.139 & 0.213 \\
\hline Variation & 2.319 & 0.692 \\
\hline
\end{tabular}

Source: Communication and Works Department, Balochistan.

Note: $\quad{ }^{1}$ Includes Musakhel and Barkhan

${ }^{2}$ Includes Killa Saifullah.

${ }^{3}$ Includes Jaffarabad.

${ }^{4}$ Includes Bolan and Jhal Magsi.

${ }^{5}$ Includes Awaran.

\section{SOCIAL AND ECONOMIC ACCESSIBILITY}

In regions without roads, the construction of new roads can have substantial effects. If roads are built to connect unpopulated and previously inaccessible areas, considerable development can occur when people are able to take advantage of the new situation.

For the majority of developing regions, an improvement in personal mobility is likely to be a major discernible change and a great perceived benefit associated with road building. Improvement in social life, health, and education will probably take place. An important consequence of this view relates to feasibility studies. Changes in social life, health, and education are among the most difficult aspects to evaluate. However, omitting these gains will always underestimate the social benefits 
to be had from road construction. This argument is not to eliminate, for example, the cost benefit analysis, but different approaches should be used in combination with a monetary evaluation.

As can be understood from the discussion in the previous section, the accessibility to basic services in the developing areas is a major theme. For the districts of Balochistan an attempt is made to evaluate the accessibility to social services, viz., to hospitals, post offices, and schools. Data on the number of hospitals, post offices, and schools have been collected for the districts of Balochistan. To measure the accessibility, say, to hospitals between the regions of a different area, hospital densities must be computed. For all three types of services, the number of supply points is divided by the area of the relevant district. This provides, for example, the number of hospitals per Sq. $\mathrm{Km}$ in a district, which is the hospital density. Alternatively, it is the average area covered by a hospital. To be able to compare hospitals, post offices, and schools, index numbers are computed from the densities. A district with the highest density gets an index of 100.0 and the district with lowest density 0.0 . This provides the linear transformation for all other districts per type of service. Without such a transformation, the different types of services are incomparable as the average service area and density will vary with the type of service. For example, the service area of a hospital is larger than that of a primary school. Apart from the density of supply points, the provincial road densities in the districts are used as well, indicating the ease to get to a supply point.

As all four components of the measurement are transformed to index numbers, the weight on each index is 0.25 to provide the accessibility score of each district. Experiments show that the results are quite insensitive to changes in the weights. The accessibility scores for the regions are provided in Table 2.

Of the 16 districts, six exhibit a very low accessibility to the services of hospitals, post offices, and schools: Chagai, Kohlu, Dera Bugti, Khuzdar, Kharan, and Zhob. As can be remembered from Table 1, these districts also have very low road densities and often unbalanced networks, so they are backward regions in many aspects of accessibility.

One might argue against the present analysis and the resulting regional priorities for road construction. From an economic point of view, it may be a waste to invest in roads in these districts if there are hardly people living in these areas. A sensible counter-argument can be that accessibility to basic services in the six districts is intolerably low. From a social point of view, the present situation in these districts can well be labelled unacceptable. Without ignoring this line of reasoning, it is of course informative to investigate whether the level of accessibility in districts, viewed as supply of services, exhibits a systematic relation with demand, viz., by population of a district. This question is tackled by performing a linear regression of the accessibility score (supply) on population density (demand). The remaining columns of Table 2 summarise the results. 
Table 2

Social Accessibility Related to Population Density

\begin{tabular}{lrrr}
\hline District & Score & Fitted & Residual \\
\hline Pishin & 62.47 & 55.3877 & 7.08 \\
Chagai & 3.43 & 10.6167 & -7.19 \\
Loralai & 39.62 & 35.9711 & 3.65 \\
Zhob & 18.33 & 26.0932 & -7.77 \\
Sibi (+ Ziarat) & 56.53 & 27.1727 & 29.36 \\
Kohlu & 7.11 & 21.1614 & -14.06 \\
Dera Bugti & 13.95 & 21.7090 & -7.76 \\
Nasirabad & 88.62 & 102.5824 & -13.96 \\
Kachhi & 63.58 & 45.9852 & 17.59 \\
Kalat & 49.61 & 45.7031 & 3.90 \\
Khuzdar & 4.96 & 15.6813 & -10.72 \\
Kharan & 5.74 & 11.0255 & -5.28 \\
Lasbella & 30.37 & 28.3616 & 2.01 \\
Turbat & 29.79 & 30.9912 & -1.20 \\
Pangjur & 20.08 & 20.7151 & -0.63 \\
Gawader & 22.61 & 17.6520 & 4.96 \\
Correlation & 0.8917 & & \\
Slope & 0.9197 & & \\
Constant & 10.6167 & & \\
\hline
\end{tabular}

Source: Communication and Works Department, Balochistan.

It is noted that the district of Quetta is not included. Being dominated by the provincial capital, this district always scores the highest, whatever density is used. This might lead to the wrong conclusion of extreme accessibility, whereas congestion is a major problem in this district.

By interpreting the results of the regression, several points emerge as important. First, the correlation coefficient 0.89 is definitely acceptable for such a simple model. Second, an increase of population density is coupled with a lower increase of accessibility as the slope is less than unity. A third point to note is the estimated constant. The value of roughly 10 can be seen as a minimal requirement of accessibility. This threshold fully confirms the weak position of Chagai, Kohlu, Khuzdar, and Kharan. All the four districts also have large negative residuals, indicating that, even when related to population density, accessibility is far too low. Another large negative residual is obtained for Nasirabad, despite the fact that accessibility in this district is high. Combining this result with previous analysis for Nasirabad, the road density there is inadequate, given the high population density. The districts Zhob and Dera Bugti have low accessibility scores coupled with a large negative residual; so, basically, we end up with the same list of backward areas. 
The operational approach of accessibility applied to districts of Balochistan turns out to be a useful tool in practical analysis. Accessibility to basic services is of primary importance for any region, and in four districts of Balochistan this kind of accessibility is too low. The fact of a close correspondence between the results here and in the previous analysis of road densities is important as it fortifies both kinds of analyses.

Economic accessibility at the district level is a difficult concept to operationalise. In general, economic accessibility reflects the ease to get to the market for both producers and consumers—as can be seen from the foregoing. Now, one of the major questions is which market(s) should be investigated. In many cases, several separate markets have to be considered simultaneously, e.g., labour market, intermediate goods markets, consumer products markets, and agricultural markets. For the case of Balochistan, a lack of data on most markets is apparent. In this respect, it is however of great comfort that in Balochistan agriculture possesses a predominant position within both the economy and available statistics. By considering economic accessibility of the agricultural sector, a large portion of the provincial economy is captured. Such an approach also avoids the problems involved in weighting access to different markets.

The description of economic accessibility as the ease to get to the (agricultural) market is still rather vague. A market can be defined to be the confrontation of supply and demand. In a regional context, it can be said to be the spatial meeting-point of supply and demand. By assuming a uniform distribution of the population over an area, it is the spatial dispersion of agricultural activities which determines the (average) probability of supply and demand to meet at some location. This line of reasoning makes the percentage cultivated area within each district a good candidate to measure economic accessibility. Of course, roads are needed for supply and demand to meet each other. The two components of economic accessibility, percentage cultivated area and road density, are transformed into index numbers between 100 and 0 and each is weighted by 0.5 . The resulting index numbers for economic accessibility of districts are given in Table 3.

Apart from the economic accessibility scores, Table 3 also contains the residuals from a linear regression of scores on population densities. The interpretation of results is similar to the analysis of social accessibility. The estimated constant of 12.88 can be viewed as a basic level which should be present in all districts. Again, districts which do not meet this minimal requirement (Chagai, Khuzdar, Kharan, and Turbat) also exhibit large negative residuals. Even after a correction for population density, the economic accessibility there is insufficient. When related to population, the economic accessibility in Nasirabad and Kalat is too low, given their strongly negative residuals. Another result to note is the fact that five districts exhibit an insufficiency of social as well as economic accessibility. 
Table 3

Economic Accessibility Scores of Districts

\begin{tabular}{|c|c|c|}
\hline District & Score & Residual \\
\hline Pishin & 69.83 & 29.27896 \\
\hline Chagai & 3.88 & -10.9316 \\
\hline Loralai & 37.01 & 0.817144 \\
\hline Zhob & 39.01 & 15.33168 \\
\hline Sibi & 50.62 & 26.81336 \\
\hline Kohlu & 35.07 & 14.86593 \\
\hline Dera Bugti & 27.06 & 6.179135 \\
\hline Nasirabad & 73.07 & -9.61668 \\
\hline Kachhi & 32.76 & -2.06962 \\
\hline Kalat & 21.99 & -12.6957 \\
\hline Khuzdar & 0.26 & -17.4315 \\
\hline Kharan & 0.00 & -16.7075 \\
\hline Lasbella & 17.78 & -3.38603 \\
\hline Turbat & 11.45 & -15.501 \\
\hline Pangjur & 16.70 & -1.26977 \\
\hline Gawader & 17.64 & -3.67673 \\
\hline Correlation & 0.76 & \\
\hline Slope & 0.58 & \\
\hline Constant & 12.88 & \\
\hline
\end{tabular}

Source: Communication and Works Department, Balochistan.

One might argue against the use of percentage cultivated area and favour, for example, land-productivity or total production. In the measurement of economic accessibility, however, it is the sheer existence of roads which counts, while production or productivity is related foremost to the capacity of roads. This view is fully confirmed by empirical analysis. Land-productivity and road density have no significant relationship in Balochistan. The same conclusion holds for road density and the sum of excess demand and excess supply within each region (ESD). The latter variable reflects the total volume of agricultural transport through a district as both regional imports and regional exports use the road network. Using the balance of a network to proxy its capacity, a regression can be performed on the ESD variable:

Balance $=0.139+0.77 *$ ESD

Correlation : 0.63 . 
The sum of excess demand and excess supply has a significant impact on the capacity of the road system, measured by the balance, with a $T$-statistic slightly above 3. This outcome enforces the present choice of measuring economic accessibility, namely, by land utilisation.

The ESD variable is based on the production and consumption of the four major agricultural products of Balochistan: wheat, rice, vegetables, and fruit. The ratio of supply and demand in Balochistan for wheat and vegetables indicates a situation close to self-support. The most important growth potential of Balochistan is discovered by the ratio of supply and demand for fruit. Most districts have a large excess supply of fruit. Such a comparative advantage should be exploited by local processing of the excess supply of fruit, provided electricity and water are available. The use of this enormous potential not only induces economic growth but also provides for a fair spread over the Province. The comparative advantage of Balochistan in fruit production seems to be a rare opportunity to stimulate economic development.

\section{CONCLUDING REMARKS}

A road network is a system of interconnected roads with different service functions. Important traffic flows are vertical up and down the network. So individual road sections are of little importance if they are not part of a system providing a continuity in the movements between the origin and the destination. This not only puts an emphasis on systematic maintenance but also necessitates an integrated design. Without a long-term view of the development of the road network, it is hard to enforce coordination or to adjudge the construction of individual roads.

Empirical analysis shows the road network of Balochistan to be in a deplorable state. The coverage and balance are insufficient, and the regional variation especially of coverage is large. A simple analysis of coverage and balance indicates priority candidates for road construction.

The districts of Chagai, Kohlu, Dera Bugti, Khuzdar, Kharan, and Turbat possess very low densities and quite unbalanced networks. Refinements are obtained by investigating social and economic accessibility. In social accessibility, Chagai, Kohlu, Khuzdar, and Kharan have low scores. With respect to economic accessibility, Chagai, Khuzdar, Kharan, and Turbat need a priority for road construction. For accessibility, it is the sheer existence of roads which counts. There seems to exist an economic rationale for the regional spread of balance, which is lacking for coverage. Coupled with the regional variation of coverage, this puts an emphasis on the construction of (all-weather) single roads.

The present paper is not intended to solve all problems in the road network of Balochistan. However, it does aim at improved coordination, reduction of fragmentation, and systematic maintenance of major roads. Economic development, 
as the theoretical framework, introduces a spatial trade-off between efficiency and equity in the road network. Empirical analysis operationalises these concepts by studying economic and social accessibility in districts of Balochistan. The results show that several clear priorities can be derived, which can serve as an input for the design of the future road network in Balochistan.

\section{BIBLIOGRAPHY}

Alder, Hans A. (1987) Economic Appraisal of Transport Projects. Washington, D. C.: International Bank for Reconstruction and Development/The World Bank.

Aken, J. van (1986) Performance Audit Guidelines — Road Transport. Islamabad.

Asian Development Bank ( 1990) Assisted Farm to Market Roads Project Phase II. Islamabad: Ministry of Local Government and Rural Development.

Fromm, Gary (1965) Transport Investment and Economic Development. Washington, D. C.: Brookings Institute.

Hoover, Edgar M., and Frank Giarratani (1971) An Introduction to Regional Economics. New York: Alfred A. Knopf. 3rd edition, 1985.

Looney, R. E. (1992) Infrastructural Constraints on Transport and Communications, the Case of Pakistan. International Journal of Transport Economics 19:3.

Richardson, Harry W. (1978) Regional and Urban Economics. New York: Penguin Books.

Rondinelli, Dennis A. (1985) Applied Methods of Regional Analysis - The Spatial Dimension of Development Policy. Boulder and London: Western Press.

Schofield, J. A. (1989) Cost-benefit Analysis in Urban and Regional Planning. London: Unwin Hyman. 